\title{
Truncated Core/NS3 Fusion Protein of HCV Adjuvanted with Outer Membrane Vesicles of Neisseria meningitidis Serogroup B: Potent Inducer of the Murine Immune System
}

\author{
Soheila Hekmat ${ }^{1}$, Seyed Mehdi Sadat ${ }^{1}$, Mohammad Mehdi Aslani ${ }^{2}$, Mehdi \\ Mahdavi $^{3}$, Azam Bolhassani ${ }^{1}$, Fateme Asgar Halvaee ${ }^{1}$, Seyed Mohammad Mahdi \\ Ghahari $^{1}$, Mohammad Reza Aghasadeghi ${ }^{1^{*}}$ and Seyed Davar Siadat ${ }^{4^{*}}$ \\ ${ }^{1}$ Department of Hepatitis and AIDs, Pasteur Institute of Iran, Tehran, Iran; ${ }^{2}$ Department of Microbiology, \\ Pasteur Institute of Iran, Tehran, Iran; ${ }^{3}$ Recombinant Vaccine Research Center, Tehran University of Medical Sciences, \\ Tehran, Iran; ${ }^{4}$ Department of Mycobacteriology and Pulmonary Research, Pasteur Institute of Iran, Tehran, Iran
}

Received 16 May 2018; revised 16 July 2018; accepted 28 July 2018

\begin{abstract}
Background: A licensed vaccine against hepatitis $\mathrm{C}$ virus $(\mathrm{HCV})$ has not become available to date. The stability and antigenicity of a targeted synthesized recombinant fusion protein consisting of a truncated core and NS3 $(\mathrm{rC} / \mathrm{N})$ of HCV had been predicted. Although safe antigens, recombinant proteins are not efficacious vaccines without adjuvants. The present study evaluated the immunogenicity of $\mathrm{rC} / \mathrm{N}$ as a bipartite antigen accompanied by Neisseria meningitidis serogroup B outer membrane vesicles (NMB OMVs) in BALB/c mice. Methods: The NMB OMVs were produced and evaluated accurately. The administrations were as follows: $\mathrm{rC} / \mathrm{N}-\mathrm{OMV}, \mathrm{rC} / \mathrm{N}-\mathrm{Freund}$ 's complete/incomplete adjuvant (CIA), rC/N-MF59, rC/N, OMV, MF59, and PBS. The production of Th1 (IFN- $\gamma$, IL2)/Th2 (IL-4)/Th17 (IL-17) cytokines and granzyme B (cytotoxic indicator) by splenic mononuclear cells and the humoral concentration of total IgG/IgG1 (Th2)/IgG2a (Th1) in sera of mice were measured using mouse ELISA kits. Results: Concentrations of Th1/Th2/Th17 cytokines, granzyme B, and immunoglobulins in the spleens and sera of immunized mice, which had received antigen plus each adjuvant ( $\mathrm{rC} / \mathrm{N}-\mathrm{OMV}, \mathrm{rC} / \mathrm{N}-\mathrm{Freund}$ 's $\mathrm{ClA}$, and $\mathrm{rC} / \mathrm{N}-\mathrm{MF59}$ ), significantly raised compared to the controls ( $\mathrm{rC} / \mathrm{N}, \mathrm{OMV}, \mathrm{MF59}$, and PBS). Th1-type responses were dominant over Th2-type responses in vaccinated mice with $\mathrm{rC} / \mathrm{N}-\mathrm{OMV}$, and Th2 type responses increased dominantly in vaccinated mice with $\mathrm{rC} / \mathrm{N}-\mathrm{MF59}(p<0.05)$. Conclusion: NMB OMVs were able to increase Th1 immune responses dramatically more than MF59 and Freund's CIA. The formulation of $\mathrm{rC} / \mathrm{N}$ with $\mathrm{NMB}$ OMVs showed its ability to induce Th1, Th2, and Th17 immune responses. rC/N-NMB OMVs is a promising approach for the development of an HCV therapeutic vaccine. DOI: 10.29252/ibj.23.4.235
\end{abstract}

Keywords: Adjuvants, Hepatitis C virus, Immunization, Vaccines

\section{Corresponding Authors:}

Mohammad Reza Aghasadeghi

Department of Hepatitis and AIDS, Pasteur Institute of Iran, Tehran, Iran; Tel.: (+98-21) 66969291; Fax: (+98-21) 66969291;

E-mail: mrasadeghi@pasteur.ac.ir

Seyed Davar Siadat

Department of Mycobacteriology and Pulmonary Research, Pasteur Institue of Iran, Tehran, Iran; Tel.: (+98-21) 66953311;

Fax: (+98-21) 66953311; E-mail: d.siadat@gmail.com

\section{INTRODUCTION}

A pproximately, 71 million people around the world are living with chronic hepatitis $\mathrm{C}$ virus (HCV) infection. Some complications such as cirrhosis and hepatocellular carcinoma (HCC) are more likely to occur in a significant number of individuals with this disease. Around 399,000 people suffering from $\mathrm{HCV}$ die each year. Although $\mathrm{HCV}$ is a curable disease, only $1.5 \%$ of infected patients have access to 
medication $^{[1]}$. Currently, there is no effective and licensed vaccine available to provide treatment or protection against $\mathrm{HCV}$ infection ${ }^{[2]}$. In about $25 \%$ of $\mathrm{HCV}$ patients, the virus is spontaneously self-limiting after elevations in $\mathrm{CD}^{+}$cytotoxic $\mathrm{T}$ lymphocytes (CTLs), $\mathrm{CD}^{+} \mathrm{T}$ helper cells (Th cells), and neutralizing antibodies. Therefore, an effective vaccine against chronic $\mathrm{HCV}$ infection may be due to the balance between cellular-mediated and humoralmediated immune responses ${ }^{[3,4]}$.

One of the most important targets of HCV therapeutic vaccines is the prevention of chronicity of infection and the prevention of cell damage (cirrhosis and HCC) by increased cellular immune responses. Despite the preference of DNA vaccine to induce Th1 immune responses, this type of vaccination has a risk of potentially disrupting normal cellular processes. This is a major concern that the introduction of foreign DNA into the host cells could affect normal protein expression pathways of the cell. Thus, fusion proteinand peptide-based vaccines are safer than DNA- and viral vector-based vaccine for the prevention of cirrhosis and $\mathrm{HCC}^{[5-7]}$.

Structural [core, envelope (E) 1 and 2, p7] and nonstructural [(NS)2, NS3, NS4A, NS4B, NS5A and NS5B] proteins of $\mathrm{HCV}$ have been considered as candidate antigens for inclusion in a multicomponent and Th1/Th2-oriented vaccine ${ }^{[7,8]}$. Core, NS3, and NS4 were specially under focus to develop therapeutic vaccine against $\mathrm{HCV}$ (Okairos, IC41, Inter cell AG) and completed phases I and II of clinical trial ${ }^{[6,7]}$. Core and NS3 are both the most conserved proteins of $\mathrm{HCV}$. Due to the induction of CTLs and Th cells, the humoral immune activity and eventual clearance of the virus by the immune system have been considered in various therapeutic vaccine development studies ${ }^{[9-14]}$. However, the full-length NS3 protein has serine protease and RNA helicase enzymatic activities, and it has immunosuppressive effects on antigen presenting cells, which are noxious to the host ${ }^{[12-14]}$. Furthermore, the full-length core protein has autoimmune activity, which may be harmful to humans and results in immune suppression/modulation in animal models $^{[9-11,13]}$.

Three adenoviral constructs expressing the middle region of the core gene and consisting of some parts of D1 and D2 (aa 50-160) and the middle region of NS3 consisting of protease and helicase (aa 1095-1387) have been developed by Hosseini et al. ${ }^{[15,16]}$. In order to retain the conformational structure and more immune response of the recombinant core, the fulllength of core D1 (aa 1-118) with a flexible linker (AAY) and proteasome cleavable site and also the middle region of $\mathrm{NS} 3$ in fused form $(\mathrm{rC} / \mathrm{N})$ were produced without $\mathrm{C}$-terminal domains of core, and without $\mathrm{N}$ and C-terminal sequences of NS3. As a result, the harmful activities of core and also enzymatic activities of the full-length of NS3 will be eliminated $^{[17]}$. In this regard, the bipartite-truncated recombinant protein $(\mathrm{rC} / \mathrm{N})$, as a new vaccine candidate, was analyzed using bioinformatic software, synthesized and carefully evaluated ${ }^{[17]}$.

Although the recombinant protein vaccines are safe and purposeful, such vaccines typically evokes weak immunity. Hence it is necessary to include one or more immune-stimulatory components in the vaccine formulation to induce potent, targeted and prolonged immune responses against the administered antigen $^{[18,19]}$. Most of the substances constituting a major potential source of adjuvants are unable to receive FDA approval for use in human vaccine formulations. Thus, there is an essential need for safer, non-toxic and more effective adjuvants, especially to stimulate both Th1 and Th2 immune responses against co-inoculated antigens for protection against many pathogens ${ }^{[20-22]}$. Among licensed adjuvants, those with microbial origin are more notable ${ }^{[21]}$. The outer membrane vesicles (OMVs) are naturally nonreplicating and highly immunogenic, mostly derived from Gram-negative bacteria. Detergent-generated vesicles are safe and able to trigger the production of numerous pro-inflammatory cytokines ${ }^{[23-25]}$. The vesicles are spherical nanoparticles (50-300 $\mathrm{nm}$ in diameter) and consist of phospholipids, lipopolysaccharide (LPS), outer membrane proteins (OMPs), and entrapped periplasmic components of their parents ${ }^{[26,27]}$. Neisseria meningitidis serogroup B OMVs (NMB OMVs) have shown evidence of potency and safety, even as a vaccine in infants, against meningococcal meningitis ${ }^{[27-29]}$ and also as an adjuvant to promote cellular and humoral immune responses in a broad range of viral and bacterial vaccines ${ }^{[26,30-32]}$. The OMVs of Escherichia coli are also used as an adjuvant and delivery system for cancer immunotherapy in mice ${ }^{[33]}$.

The present study aimed to prescribe concurrently the NMB OMVs, as an adjuvant, with the truncated recombinant core ${ }_{1-118}$ (rCore) and $\mathrm{NS}_{1095-1384}$ (rNS3) fusion protein $(\mathrm{rC} / \mathrm{N})$ of $\mathrm{HCV}$ to evaluate the probable immune responses against $\mathrm{HCV}$ in a murine model.

\section{MATERIALS AND METHODS}

\section{$\mathrm{rC} / \mathrm{N}$ fusion protein production}

The rC/N fusion protein was previously prepared ${ }^{[17]}$. Briefly, the first domain of the core (amino acid residues 1-118), an AAY linker, and the middle region of NS3 (aa 1095-1384) were cloned into the pET 24a (+) vector, expressed in E. coli BL21-DE3, purified by 
affinity chromatography and finally analyzed by SDSPAGE and Western blotting using anti-6× His tag monoclonal antibody.

\section{NMB OMVs preparation and analysis}

NMB OMVs were prepared as described before ${ }^{[26]}$. In brief, the NMB strain (CSBPI, G-245) was grown under controlled submerged cultural conditions in a fermentor containing modified Frantz medium at $36 \pm$ $1{ }^{\circ} \mathrm{C}$ for $24 \mathrm{~h}$, up to the early stationary phase. OMVs were released into $0.1 \mathrm{M}$ of Tris- $\mathrm{HCl}$ buffer, $\mathrm{pH} 8.6$, containing $10 \mathrm{mM}$ EDTA and $0.5 \% \mathrm{w} / \mathrm{v}$ sodium deoxycholate. Purification of the OMVs was done by centrifugation at $20,000 \times \mathrm{g}$ for 30 minutes, followed by ultracentrifugation at $125,000 \times \mathrm{g}$ for $2 \mathrm{~h}$. The sediment of vesicles was homogenized in PBS, $\mathrm{pH}$ 7.2, and thimerosal (100 mg/l) was added as a preservative.

\section{Analysis of NMB OMVs}

Total protein content of OMVs was measured by spectrophotometry. The protein concentration was also determined using the Bradford assay. The POR A protein of $N M B$ OMVs was analyzed on $12 \%$ SDSPAGE gel. The LPS amount in the NMB OMVs was assayed using the Limulus Amebocyte Lysate (LAL) method (Cambrex Corporation, USA), and the pyrogenicity of the OMVs was assayed in rabbit. Briefly, three out of four healthy adult New Zealand Albino rabbits, weighing between 1.8 and $3.7 \mathrm{~kg}$, were injected $(10 \mathrm{ml} /$ per $\mathrm{kg}$ body weight) with $N M \mathrm{~B}$ OMV. One rabbit was considered as the control. The rectal temperatures of each rabbit were measured at 30minute intervals between 1-3 hours subsequent to the injection $^{[28]}$

\section{Morphology of $\mathrm{NMB} \mathrm{OMVs}$}

An Atomic Frorce Microscope (AFM, Nano Wizard II nano-science AFM, JPK Instruments Inc., Germany) and JPK data processing software were used to observe the morphology of NMB OMVs. Mean size distribution, polydispersity index (PDI), and zeta potentials of the $N M \mathrm{~B}$ OMVs were determined by dynamic light scattering (Zetasizer Nano ZS; Malvern Instruments, Malvern, UK) at $25^{\circ} \mathrm{C}$.

\section{Antigen formulation \\ The $\mathrm{rC} / \mathrm{N}$ protein alone and admixed forms $(\mathrm{rC} / \mathrm{N}$ - OMV, rC/N-Freunds CIA, and rC/N-MF59) were prepared for immunization. Each dose contained $20 \mu \mathrm{g}$ of $\mathrm{rC} / \mathrm{N}$ admixed with $40 \mu \mathrm{g}$ of adjuvant in a total volume of $100 \mu \mathrm{l}$ sterile PBS and was shaken vigorously.}

\section{Experimental groups and immunization schedule}

Pathogen-free 6-8-week-old female BALB/c mice were divided into seven groups, each consisting of six animals housed according to international animal care ethics and immunized subcutaneously with $\mathrm{rC} / \mathrm{N}$, rC/N-OMV, rC/N-Freund's CIA, and rC/N-MF59. The MF59, OMV, and PBS were used as controls. Each mouse received $20 \mu \mathrm{g} \mathrm{rC} / \mathrm{N}$ alone or emulsified in 40 $\mu \mathrm{g}$ of each adjuvant in a total volume of $100 \mu \mathrm{l}$. Booster injections were given three and six weeks after the first prescriptions.

\section{Total antibody and isotypes assay}

Blood was collected from immunized mice by retroorbital bleeding two weeks after the third immunization, and the sera were stored at $-20{ }^{\circ} \mathrm{C}$ until use. An ELISA was used to determine humoral responses. Briefly, $1 \mu \mathrm{g} / \mathrm{ml}$ of $\mathrm{rC} / \mathrm{N}$ or rCore or $\mathrm{rNS} 3$ protein in PBS was added to each well of 96-well ELISA Maxisorp plates (Nunc, Naperville, IL, USA) and incubated at $4{ }^{\circ} \mathrm{C}$ overnight. Plates were washed with washing buffer (PBS containing $0.05 \%$ Tween 20) and blocked at $37{ }^{\circ} \mathrm{C}$ for $1 \mathrm{~h}$ using the blocking buffer (PBS containing $0.05 \%$ skimmed milk). The wells were washed, and serial dilutions of sera from 1:50 to $1: 102400$ were added to each well and incubated at $37{ }^{\circ} \mathrm{C}$ for $1.5 \mathrm{~h}$. Then the wells were washed and incubated with 1:10,000 dilution of antimouse antibody HRP conjugate (Sigma, USA) for 1.5 $\mathrm{h}$. The washing step was repeated, and the plate was incubated with TMB substrate in the dark for $30 \mathrm{~min}$. The reaction was stopped with $2 \mathrm{~N} \mathrm{H}_{2} \mathrm{SO}_{4}$, and color density was measured at $\mathrm{OD}_{450} \mathrm{~nm}$. The specific IgG1 and IgG2a subclasses were detected using goat antimouse IgG1 and IgG2a secondary antibodies (Sigma, USA) according to the manufacturer's instructions.

\section{Cytokine assay}

Three weeks after the last booster injection, the spleen of each mouse was dissected under sterile conditions, crushed and suspended in cold PBS containing $2 \%$ fetal bovine serum. Red blood cells were lysed, and a total number of $2 \times 10^{5}$ splenocytes in $100 \mu \mathrm{l}$ suspension were seeded on each well of a 24well plate using complete RPMI 1640 (Gibco, Germany), supplemented with $10 \%$ FBS and $4 \mathrm{mM}$ of L-glutamine and stimulated in vitro with $10 \mu \mathrm{g} \mathrm{rC} / \mathrm{N}$ incubated in $5 \% \quad \mathrm{CO}_{2}$ at $37{ }^{\circ} \mathrm{C}$ for $72 \mathrm{~h}$. The supernatants were collected and stored at $-70{ }^{\circ} \mathrm{C}$ util use. The concentrations of IFN- $\gamma$, IL-4, IL-2, and IL-17 cytokines were estimated using ELISA Kits (eBioscience, San Diego, CA, USA) according to the manufacturer's instruction. The concentration of each sample was calculated according to the standard curve. 


\section{Granzyme B assay}

The amount of granzyme B in the supernatant of cultured spleen cells was measured according to the Mouse Granzyme B ELISA kit instructions (Invitrogen by Thermo Fisher Scientific, Affymetrix, USA) using a quantitative sandwich ELISA assay. Several dilutions of granzyme B were used to adjust a calibration curve for determination of accurate granzyme B concentration in the sample. All wells were stimulated by $\mathrm{rC} / \mathrm{N}$, and few wells belonged to OMV-rC/N immunized group were prepared by antigen without any stimulation. Samples and standards were assayed at an optical density (OD) of $450 \mathrm{~nm}$.

\section{Statistical analysis}

The graphPad Prism 6.01 software was employed to evaluate differences between the experimental groups using one-way and two-way analysis of variance (ANOVA), followed by Tukey's or Holm-Sidak's multiple comparisons tests. Values of $p<0.05$ were considered statistically significant.

\section{RESULTS}

\section{Confirmation and safety of NMB OMVs}

The protein content of OMVs determined by spectrophotometry was $1.2 \mathrm{mg} / \mathrm{ml}$, and the SDS-PAGE pattern confirmed the presence of POR A of $N M B$ OMVs as class one OMP with a 45-kDa band (Fig. 1). The LAL test showed $0.8 \mathrm{EU} / \mathrm{ml}$ endotoxin activity. No rabbits showed individual temperature rises of $0.6^{\circ} \mathrm{C}$, and by utilizing NMB OMVs, the test met the requirements for the absence of pyrogeny. AFM scanning showed the uniformity and spherical morphology of the OMVs (Fig. 2). The absolute value of NMB OMVs' zeta potential was 38.1 (| -38.1 | = $38.1 \mathrm{mV}$; Fig. 3A), and their zeta average size was 184.2 (d. nm; Fig. 3B). The heterogeneity index or PDI of vesicles was 0.178 (Fig. 3B).

\section{Humoral immune responses and isotyping}

The results showed that immunizing mice with the candidate $\mathrm{rC} / \mathrm{N}-\mathrm{OMV}$ vaccine induced higher levels of total antibody in the experimental groups compared with the controls (PBS, OMV, and MF59; $p<0.05$; Fig. 4A). The results of total immunoglobulin titration in mice immunized with $\mathrm{rC} / \mathrm{N}-\mathrm{OMV}$ showed that the $\mathrm{rC} / \mathrm{N}$ fusion protein was able to induce specific humoral responses more than rCore or rNS3 alone or the controls $(p<0.05$; Fig. 4B). The rate of IgG1 in $\mathrm{rC} / \mathrm{N}-\mathrm{OMV}$ showed significant differences versus $\mathrm{rC} / \mathrm{N}$ $(p<0.05), \operatorname{MF59}(p=0.0012)$, OMV $(p=0.0004)$, and PBS $(p=0.0004$; Fig. 5A). There are significant differences between the $\mathrm{rC} / \mathrm{N}-\mathrm{OMV}$ and the control

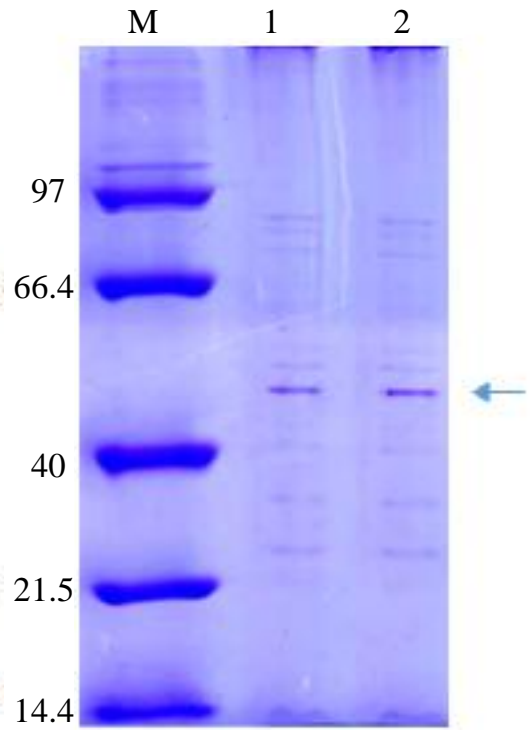

Fig. 1. Confirmation of the $N M \mathrm{~B}$ OMVs by SDS-PAGE. Lines 1-2, NMB OMVs; M, marker (14.4-97 kDa); Por A protein belonging to $N M \mathrm{~B}$ OMP confirmed by a dominant $45-$ KDa bond in the SDS-PAGE pattern.

groups (MF59, OMV, and PBS) in the induction of IgG2a ( $p=0.0003,0.0004$, and 0.0001 , respectively) in the sera of mice (Fig. 5B). The measurements of the antibody isotypes showed that the $\operatorname{IgG} 2$ a level rose in the sera of the mice that received $\mathrm{rC} / \mathrm{N}$ accompanied by OMV more than other immunized mice groups $(p<$ 0.05). The IgG2a isotype is an indicator for Th1/cellular response ${ }^{[34]}$. The ratio of IgG2a concentration in splenocytes of mice that received $\mathrm{rC} / \mathrm{N}-\mathrm{OMV}$ was higher than all other vaccinated and control groups. It seems that OMV, as an adjuvant, is able to induce an $\mathrm{IgG} 2 \mathrm{a}$ response more than MF59 and Freund's CIA ( $p<0.05$; Fig. 5B).

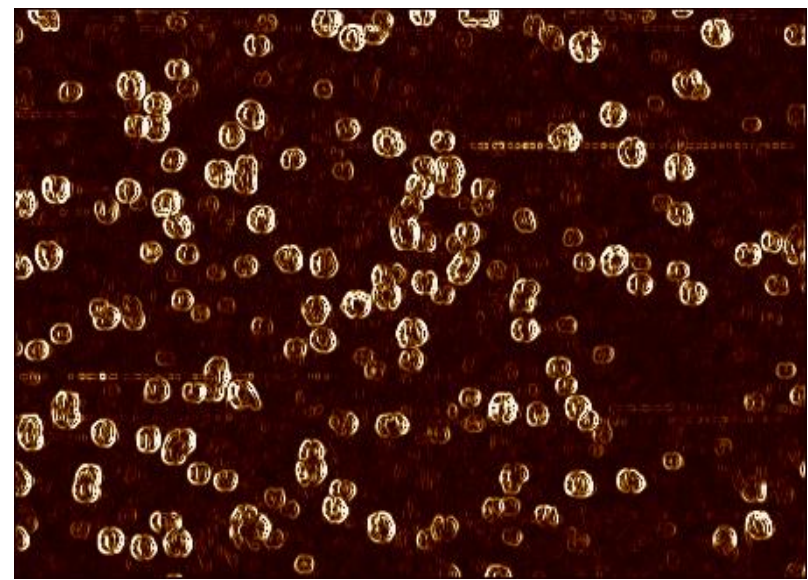

Fig. 2. Atomic Force Microscopic (AFM) presentation of NMB OMVs. The selected channel to process was error signal trace mode (fast $1.788 \times$ slow $1.152 \mu \mathrm{m}$ ). 

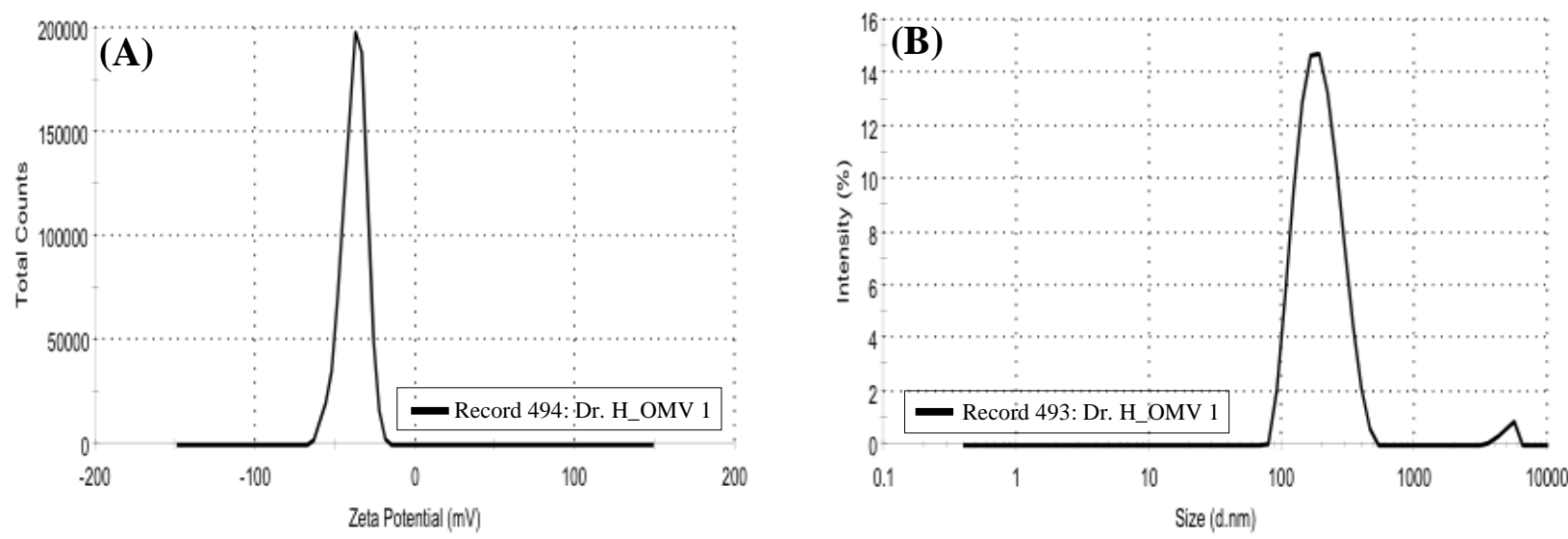

Fig. 3. Dynamic light scattering analysis of $N M B$ OMVs. (A) Zeta potential distribution of NMB OMVs; (B) Size distribution by intensity or zeta average and PDI.

\section{Evaluation of IFN- $\gamma$, IL-2, IL-4, and IL-17}

The concentrations of IFN- $\gamma$, IL-2, IL-4, and IL-17 cytokines from $\mathrm{rC} / \mathrm{N}$-stimulated mononuclear cells of spleens from mice groups vaccinated with or without adjuvant $(\mathrm{rC} / \mathrm{N}, \mathrm{rC} / \mathrm{N}-\mathrm{OMV}, \mathrm{rC} / \mathrm{N}-\mathrm{MF} 59$, and $\mathrm{rC} / \mathrm{N}-$ Freund's CIA), and the controls were evaluated three weeks after the final booster injections. The results are shown in Figure 6.

As depicted in Figure 6A, the concentration of IFN- $\gamma$ cytokine in the experimental groups after the injection of $\mathrm{rC} / \mathrm{N}, \mathrm{rC} / \mathrm{N}$ adjuvanted with $N M \mathrm{~B}$ OMVs, MF59 or Freund's CIA significantly increased compared with the control groups $(p<0.05)$. No significant difference was observed among the control groups $(p>0.05)$. The rate of IFN- $\gamma$ in mice immunized with $\mathrm{rC} / \mathrm{N}-\mathrm{OMV}$ differed significantly from the groups that received OMV ( $p=0.001)$, PBS $(p=0.0007)$, or not stimulated with any antigen $(p=0.0006)$. The concentration of IFN- $\gamma$ was significantly higher in the group of mice immunized with rC/N-MF59 than in the control groups $(p<0.005)$. The level of this cytokine in mice vaccinated with rC/N-Freund's CIA differed significantly from that of the control groups $(p<$ 0.005). The mice immunized with the $\mathrm{rC} / \mathrm{N}$ were significantly different from the control groups $(p<$ $0.05)$.

Immunization with all formulations of vaccines (rC/N-OMV, rC/N-MF59, and rC/N-Freund's CIA) significantly increased IL-4 producing lymphocytes compared with the control groups $(p<0.005)$. The difference was greater between the rC/N-MF59 recipient group and the control groups for IL-4 than with other vaccinated groups $(p<0.0001)$. This group was significantly different from $\mathrm{rC} / \mathrm{N}$ alone as well $(p<0.05)$. The intra-group comparison showed significant difference among rC/N-MF59 and other vaccine recipient groups $(p>0.05)$. Moreover, no significant intra-group difference was observed among the control groups ( $p>0.05$; Fig. 6. B).
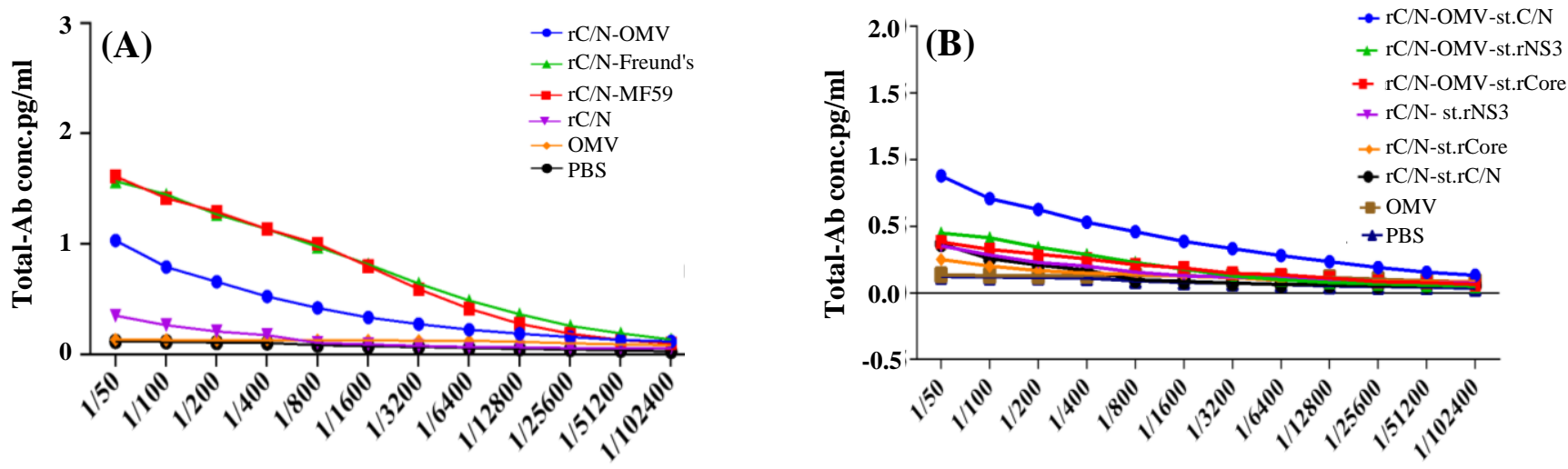

Fig. 4. Total antibody in immunized mice. (A) Total antibody in mice immunized with candidate rC/N-OMV vaccine, rC/N-MF59, $\mathrm{rC} / \mathrm{N}$-Freund's $\mathrm{CIA}, \mathrm{rC} / \mathrm{N}, \mathrm{OMV}$, and $\mathrm{PBS}$ after in vitro stimulation with $\mathrm{rC} / \mathrm{N}$ protein. The rates of antibody were significantly higher in the vaccine groups than in the control groups $(p<0.05)$. The rates of total antibody in mice immunized with rC/N-MF59 and rC/NFreund's CIA were more than the vaccinated group with $\mathrm{rC} / \mathrm{N}-\mathrm{OMV}(p<0.05)$; (B) total antibody in $\mathrm{rC} / \mathrm{N}-\mathrm{OMV}$ stimulated with $\mathrm{rC} / \mathrm{N}$ was higher than $\mathrm{rC} / \mathrm{N}-\mathrm{OMV}$ stimulated with rCore, rNS3, or the controls $(p<0.05)$. 
(A)

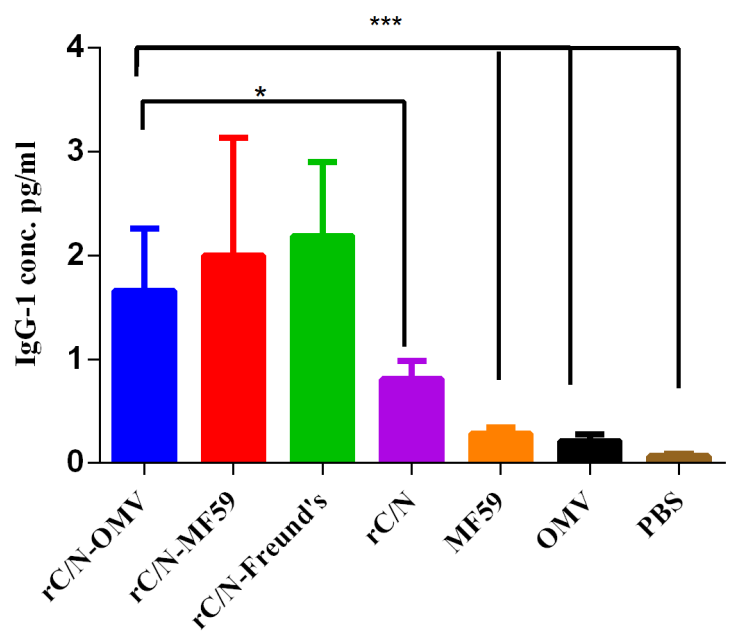

(B)

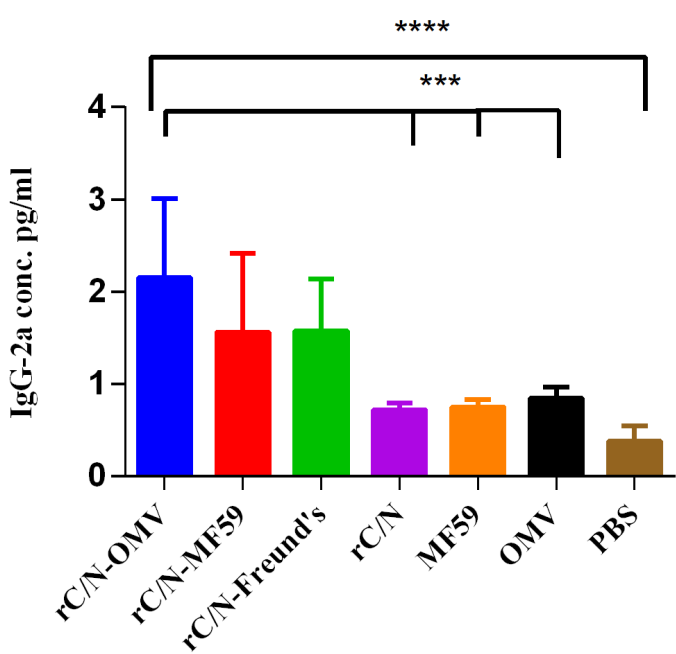

Fig. 5. One-way ANOVA of specific humoral antibodies followed by Holm-Sidak's multiple comparisons test. (A) The level of IgG1 in $\mathrm{rC} / \mathrm{N}-\mathrm{OMV}$ was significantly higher vs. $\mathrm{rC} / \mathrm{N}(p<0.05)$ and vs. MF59, OMV, and PBS $(p<0.0005)$. (B) the level of IgG2a in the candidate $\mathrm{rC} / \mathrm{N}-\mathrm{OMV}$ vaccine was significantly higher vs. $\mathrm{rC} / \mathrm{N}(p<0.0005)$, MF59 $(p=0.0003)$, OMV $(p=0.0004)$, and PBS $(p$ $=0.0001)$. The levels of significancy are indicated by stars as follows: ${ }^{*} p<0.05,{ }^{* * *} p<0.0005$, and ${ }^{* * * *} p<0.0001$.

The splenocytes from the immunized mice with vaccine groups ( $\mathrm{rC} / \mathrm{N}-\mathrm{OMV}, \mathrm{rC} / \mathrm{N}-\mathrm{MF} 59$, and $\mathrm{rC} / \mathrm{N}-$ Freund's CIA) showed significant proliferation and production of the IL-2 cytokine immune response compared with the control groups $(p<0.0005)$. The level of IL-2 was significantly different from the $\mathrm{rC} / \mathrm{N}$ vaccinated group, as compared with the control groups $(p<0.05)$. The IL-2 concentration in all groups vaccinated with $\mathrm{rC} / \mathrm{N}$ accompanied with adjuvants (OMV, MF59, and Freund's CIA) was significantly different from that in the group receiving $\mathrm{rC} / \mathrm{N}$ alone $(p$ $<0.05$; Fig. 6C).

As seen in Figure 6D, the pro-inflammatory IL-17 producing lymphocytes up-regulated significantly in the spleen of mice immunized with $\mathrm{rC} / \mathrm{N}-\mathrm{OMV}(p<$ $0.0001), \mathrm{rC} / \mathrm{N}-\mathrm{MF} 59(p<0.0005), \mathrm{rC} / \mathrm{N}-F r e u n d$ 's CIA $(p=0.0005)$, and $\mathrm{rC} / \mathrm{N}(p<0.005)$ vs. OMV, PBS, and no stimulation with any antigen. The level of IL-17 was approximately equivalent in the groups immunized with rC/N-Freund's CIA, rC/N-MF59, and rC/N-OMV $(p>0.05)$. Although the addition of adjuvants to $\mathrm{rC} / \mathrm{N}$ protein increased the level of IL-17, no significant difference based on adjuvant type was observed.

\section{Comparison of cytokines}

The ratios of cytokines (IFN- $\gamma$, IL-2, IL-4, and IL17) producing lymphocytes in the spleen of the immunized mice were compared with each other (Fig. 7). With respect to the comparative cytokines profile, the levels of the Th1 (IFN- $\gamma$ and IL-2) immune response in immunized group with $\mathrm{rC} / \mathrm{N}-\mathrm{OMV}$ group was significantly higher than Th2 (IL-4) and Th17 (IL-
17) immune responses ( $p<0.05$; Fig. 7A). The level of IFN- $\gamma$ was significantly higher than IL-4 $(p<005)$ and IL-17 $(p<0.0001)$ in vaccinated mice group with the $\mathrm{rC} / \mathrm{N}-\mathrm{OMV}$. The level of IFN- $\gamma$ in spleen of vaccinated group with $\mathrm{rC} / \mathrm{N}-\mathrm{OMV}$ was significantly higher than the vaccinated mice group with rC/N-MF59 ( $p<$ 0.005) (Fig. 7B).

\section{Cytotoxic activity}

The rate of granzyme B in the spleens of immunized mice was significantly higher in the vaccinated groups (rC/N-Freund's CIA, rC/N-MF59, and $\mathrm{rC} / \mathrm{N}-\mathrm{OMV}$ ) in comparison with the control groups $[\mathrm{rC} / \mathrm{N}(p<0.005)$, OMV $(p<0.005)$, PBS $(p=0.0001)]$ and no stimulation with any antigen $(p=0.0001)$, as shown in Figure 8 . There was no significant difference between the groups vaccinated with $\mathrm{rC} / \mathrm{N}$-Freund's $\mathrm{CIA}, \mathrm{rC} / \mathrm{N}$ MF59, or rC/N-OMV in inducing CTLs, natural killer (NK) cells, and cytotoxic T cells to release granzyme B $(p>0.05)$.

\section{DISCUSSION}

In order to develop an effective and safe vaccine against $\mathrm{HCV}$, our previous study was evaluated with bioinformatic online tools and produced successfully a truncated recombinant fusion protein $(\mathrm{rC} / \mathrm{N})$ consisting of core (aa 1-118) and NS3 (aa 1095-1384), as two conserved parts of $\mathrm{HCV}$, containing immunodominant epitopes ${ }^{[17]}$. In this study, the authors developed and verified $N M B$ OMVs and used these microbial-derived 
(A)

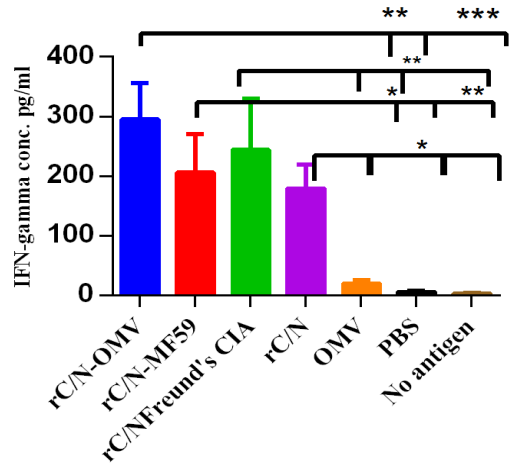

(B)

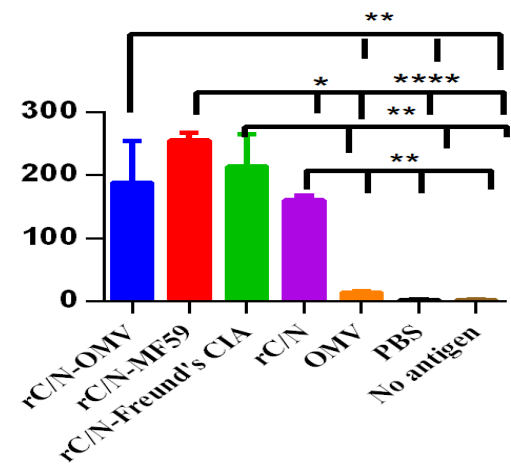

(C)

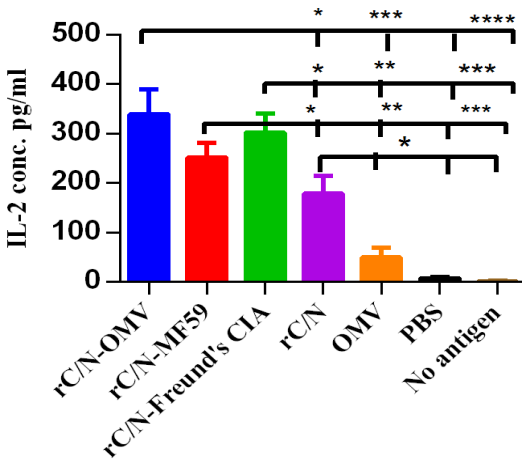

(D)



Fig. 6. Cytokines secretion analysis of spleens in immunized mice after in vitro stimulation with $\mathrm{rC} / \mathrm{N}$ protein and unstimulated with any antigen. (A) IFN- $\gamma$, (B) IL-4, (C) IL-2, and (D) IL-17 cytokines secretion. The levels of significance are indicated by stars as follows: ${ }^{*} p<0.05,{ }^{* * *} p<0.005$, **** $p<0.0005$, and ${ }^{* * * * *} p<0.0001$. particles as an immunopotentiator to overcome the limitation of low immunogenicity of $\mathrm{rC} / \mathrm{N}$ fusion protein vaccine. Analyses and evaluations in our study were performed by immunizing mice groups using $\mathrm{rC} / \mathrm{N}$ alone or in mixed forms, with NMB OMVs, MF59, or Freund's CIA adjuvants, and comparison were made with the control (OMVs, MF59, and PBS) groups.

The OMV is a reflective of the structure of the outer membrane and contains various compounds from the periplasm or cytoplasm without reproduction ability. Thus, detergent-generated vesicles are able to trigger the production of pro-inflammatory cytokines without harmful noxious effects ${ }^{[23-25,32]}$. The LAL test showed that the allowed endotoxin activity of LPS belonged to the prepared NMB OMVs $(0.8 \mathrm{EU} / \mathrm{ml})$, and they were considered safe; the authorized level of endotoxin activity for human use is less than $5 \mathrm{EU} / \mathrm{ml}$. The absolute value of $N M \mathrm{~B}$ OMVs' zeta potential was more than $30 \mathrm{mV}(38.1>30)$, indicating that the particles are in stable condition and are so small that they do not have the tendency to aggregate ${ }^{[35,36]}$. Typically, OMVs must be 50-300 $\mathrm{nm}$ in diameter. The zeta average of the achieved size [184.2 (d. nm)] matches the actual size of these particles ${ }^{[23,24,36]}$. A heterogeneity index or PDI (0.178) of less than 0.5 is an ideal indicator of uniform distribution of particles ${ }^{[35,36]}$. Thus, the physicochemical properties of OMVs indicated that they have potential to consider as adjuvants.

Cellular immune response, which is elicited by CTLs, is crucial for a therapeutic vaccine against $\mathrm{HCV}$, but an ideal anti-HCV vaccine candidate (therapeutic and anaphylactic) should include CTLs, HTLs, and Bcells to ensure robust incitation of a humoral anti-HCV immune respons $\mathrm{e}^{[3,4]}$. Immunogenicity was monitored through the ability of splenic mononuclear cells to proliferate and induce Th1 (IFN- $\gamma$ and IL-2), Th2 (IL4), and Th17 (IL-17) cytokines. Furthermore, the concentrations of specific total antibody and isotypes, as indicators of Th2 (IgG1 and Th1 (IgG2a), were detected in the sera of immunized mice groups. The rates of increase in granzyme $\mathrm{B}$ in the granules of CTLs, NK cells, and cytotoxic T cells of the spleens of vaccinated mice groups were the indicators of apoptosis and cytotoxic activity ${ }^{[37,38]}$.

The levels of total and isotype (IgG-1 and IgG-2a) immunoglobulins were significantly higher in the sera of mice immunized with $\mathrm{rC} / \mathrm{N}-\mathrm{OMV}$ compared to the control groups. The presence of IgG1 isotype is an indicator of Th2/humoral immune response, while IgG2a isotype is an indicator of Th1/cellular immune response ${ }^{[34]}$. The rate of isotypes (IgG1 and IgG2a) of antibodies showed that $\mathrm{rC} / \mathrm{N}-\mathrm{OMV}$ is able to induce humoral (Th2)- and cellular (Th1)-oriented immune responses. IFN- $\gamma$ or type II interferon, is a cytokine 
(A)

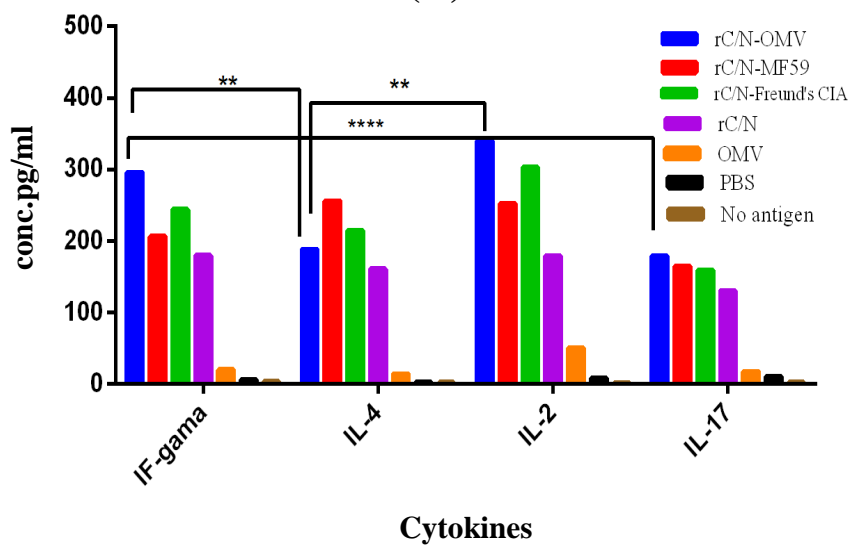

(B)

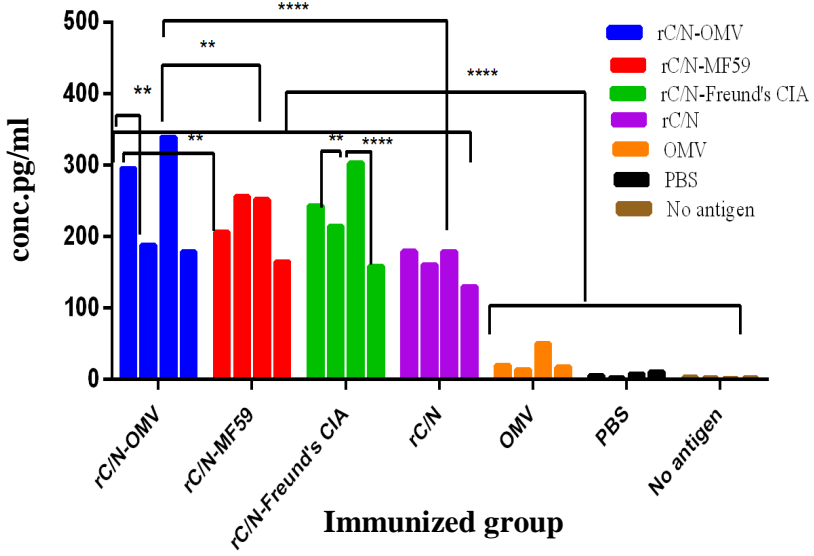

Fig. 7. Comparison of cytokines (IFN- $\gamma$, IL-2, IL-4, and IL-17) in all immunized groups. (A) Comparison of Th1 (IFN- $\gamma$ and IL-2), Th2 (IL-4), and Th17 (IL-17) cytokine secretion in the splenocytes of immunized mice groups (rC/N-OMV, rC/N-MF59, rC/NFreund's CIA, rC/N, OMV, PBS stimulated by $\mathrm{rC} / \mathrm{N}$, and no stimulated by antigen). The level of IFN- $\gamma$ and IL-2 increased significantly compared with IL-4 and IL-17 $(p<0.005)$. (B) There was a significant difference between rC/N-OMV and rC/N-MF59 vaccinated groups in the secretion of IFN- $\gamma$ and IL-2 cytokines $(p<0.005)$. The level of IL-2 was higher in splenocytes of mice immunized with $\mathrm{rC} / \mathrm{N}-\mathrm{OMV}$ than those immunized with $\mathrm{rC} / \mathrm{N}(p<0.0001)$. The levels of significance are indicated by stars as follows: ${ }^{* *} p<0.005, \stackrel{* * * *}{*} p<0.0001$.

that is critical for innate and adaptive immunity against pathogens. It has the ability to inhibit viral replication. This cytokine is produced predominantly by NK and NKT cells, by CD4 Th1 and CD8 CTL effector T cells and also by non-cytotoxic innate lymphoid cells ${ }^{[39]}$. Generally, IL-2, as a predominant cytokine that is produced during the primary response of Th cells, is required for the proliferation and differentiation of the Th precursor into functional Th cells, as well as the development of regulatory $\mathrm{T}$ cells. Thus, IL-2 is secreted by mature $\mathrm{T}$ cells to activate effector cells $^{[40-42]}$.

The levels of IFN- $\gamma$ and IL-2 cytokines, as two arms of the cellular immune response in the spleens of the mice immunized with the candidate $\mathrm{rC} / \mathrm{N}-\mathrm{OMV}$ vaccine, amplified significantly in comparison with the control groups. Thus, the $\mathrm{rC} / \mathrm{N}-\mathrm{OMV}$, as a safe candidate of vaccine, is able to strongly induce Th1-oriented (IgG2a antibody, IFN- $\gamma$, and IL-2 cytokines) responses. The data indicated that the administration of $\mathrm{rC} / \mathrm{N}$ protein accompanied by $N M \mathrm{~B}$ OMVs improved the Th2 polarized humoral-immune response as evidenced by increases in IL-4 cytokine and IgG1 antibody ratios that were less than that of rC/N-MF59.

Recently, the traditional paradigm, according to only Th1/Th2 balance, has been changed, and the distinct lineage of CD4 Th cell, called Th17, as the producer of effector molecules including IL-17, IL-17F, IL-21, IL22 , and IL-6 is undeniable ${ }^{[43]}$. The role of the Th17 cell lineage in the primary immune response has been documented, and it may be critical for vaccine-induced memory immune responses ${ }^{[43]}$. Researchers have proven that IL-17 induces protective cellular responses against several pathogens and is a connector between innate and adaptive immunity at the mucosa ${ }^{[4,45]}$. The results of the current study showed that the pro-inflammatory IL-17 producing lymphocytes in the spleens of mice immunized with the candidate rC/N-OMV vaccine amplified significantly compared with the OMV, PBS, and no antigen groups. In addition, although the presence of a protective immune response by IL-17 is evident, no significant difference

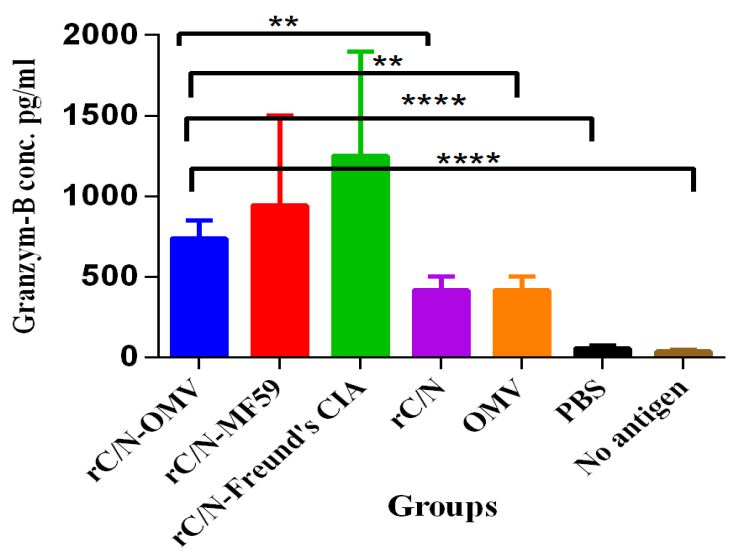

Fig. 8. Cytotoxic activity in experimental groups. The level of granzyme $\mathrm{B}$ in the spleens of the mice immunized with the candidate $\mathrm{rC} / \mathrm{N}-\mathrm{OMV}$ vaccine increased significantly compared with the $\mathrm{rC} / \mathrm{N}(p=0.0015)$, OMV $(p=0.0015)$, PBS $(p=0.0001)$, and no antigen $(p=0.0001)$ groups. The levels of significance are indicated by stars as follows: ${ }^{* * *} p<0.005$, $p<0.0001$. 
was found among the groups vaccinated with $\mathrm{rC} / \mathrm{N}$ OMV, rC/N-Freund's CIA, and rC/N-MF59. It seems that OMV, Freund's CIA, and MF59 as adjuvants are equally able to induce IL-17.

The level of all cytokines (IFN- $\gamma$, IL-2, IL-4, and IL17) in the spleen, and the total $\mathrm{IgG}$ and its isotypes (IgG1 and $\operatorname{IgG} 2 \mathrm{a}$ ) were higher in the seum of mice immunized with $\mathrm{rC} / \mathrm{N}-\mathrm{OMVs}$ than in the mice group vaccinated with $\mathrm{rC} / \mathrm{N}$ alone. Therefore, $N M \mathrm{~B}$ OMV showed its efficacy as an adjuvant beside the selected synthesized antigen $(\mathrm{rC} / \mathrm{N})$. It is noteworthy that the ratio of IFN- $\gamma$, IL-2, and IL-17 as Th1 indicators significantly increased in comparison with IL-4 (Th2 indicator) in the spleen of the mice immunized with $\mathrm{rC} / \mathrm{N}-\mathrm{OMV}$, and in the same group, the rate of $\operatorname{IgG} 2 \mathrm{a}$ (Th1 indicator) increased more than $\operatorname{IgG} 1$ (Th2 indicator). Although the candidate vaccine ( $\mathrm{rC} / \mathrm{N}$ OMV) is able to induce both cellular and humoral immune responses, it seems that the cellular response is dominant.

The release of granzyme B, as enzymatic granules, mainly from CTLs, NK cells, and cytotoxic T cells is an indicator of apoptotic and cytotoxic activity ${ }^{[37,38]}$. The present study showed a significantly greater presence of granzyme B as cytotoxic granules in the spleens of mice immunized with $\mathrm{rC} / \mathrm{N}-\mathrm{OMVs}$ than in the control groups $(p=0.0001)$. Therefore, it could be concluded that the candidate vaccine is capable of activating the apoptosis of infected cells by CTLs and NKs.

The indicators show that the $\mathrm{rC} / \mathrm{N}-\mathrm{OMV}$ group is able to induce a greater Th1 (IFN- $\gamma$, IL-2, and IgG2a) immune response than the rC/N-MF59 group, and that NMB OMV is able to induce a greater Th1 response than MF59, which has been approved for use in humans. While rC/N-MF59 is capable of inducing Th2 (IL4 and IgG1) more than the other vaccinated groups, the $\mathrm{rC} / \mathrm{N}-\mathrm{OMV}$ group is able to compete with $\mathrm{rC} / \mathrm{N}$ Freund's CIA immunized group. The highly effective Freund's CIA is used as the gold standard to evaluate vaccines under development. Indeed, $\mathrm{rC} / \mathrm{N}-N M \mathrm{~B}$ OMVs presented broad humoral and cellular immunity, and the cellular immune response was more robust than the humoral response. It also increased cytotoxicity by releasing granzyme B as apoptotic granules.

Taken together, the immunological benchmarks of $\mathrm{rC} / \mathrm{N}$ together with the safety profile of $N M \mathrm{~B} \mathrm{OMV}$ as an immunoadjuvant are evidenced to consider this candidate vaccine as an effectual combination to produce remarkable anti-HCV responses.

\section{ACKNOWLEDGEMENTS}

This study was a part of Ph.D. thesis of the first author, and financially was supported by the Pasteur Institute of Iran (Tehran).

CONFLICT OF INTEREST. None declared.

\section{REFERENCES}

1. WHO Hepatitis C. http://www.who.int/mediacentre/ factsheets/fs164/en/. (Updated October 2017)

2. Zhong DL, Zhong HJ. Hepatitis $\mathrm{C}$ virus vaccine development: old challenges and new opportunities. National science review 2015; 2(3): 285-295.

3. Thimme R, Bukh J, Spangenberg HC, Wieland S, Pemberton J, Steiger C, Govindarajan S, Purcell RH, Chisari FV. Viral and immunological determinants of hepatitis $\mathrm{C}$ virus clearance, persistence, and disease. Proceedings of the national academy of sciences of the United States of America 2002; 99(24): 15661-15668.

4. Roohvand F, Kossari N. Advances in hepatitis C virus vaccines, part two: advances in hepatitis $C$ virus vaccine formulations and modalities. Expert opinion on therapeutic patents 2012; 22(4): 391-415.

5. Khan KH. DNA vaccines: roles against diseases. Germs 2013; 3(1): 26-35.

6. Feinstone SM, Hu DJ, Major ME. Prospects for prophylactic and therapeutic vaccines against hepatitis $\mathrm{C}$ virus. Clinical infectious diseases 2012; 55 (Suppl 1): S25-S32.

7. Ghasemi F, Rostami S, Meshkat Z. Progress in the development of vaccines for hepatitis $\mathrm{C}$ virus infection. World journal of gastroenterology 2015; 21(42): 1198412002.

8. Moradpour D, Penin F. Hepatitis C virus proteins: from structure to function. Current topics in microbiology and immunology 2013; 369: 113-142.

9. Large MK, Kittlesen DJ, Hahn YS. Suppression of host immune response by the core protein of hepatitis $\mathrm{C}$ virus: possible implications for hepatitis $\mathrm{C}$ virus persistence. Journal of immunology 1999; 162(2): 931938.

10. Liu Y, Zhou W, You C, Zheng H, You H, Liu H, Zhang D, Luo R, Key HH, Hermonat PL. An autoimmune domain-reduced $\mathrm{HCV}$ core gene remains effective in stimulating anti-core cytotoxic $\mathrm{T}$ lymphocyte activity. Vaccine 2006; 24(10): 1615-1624.

11. Andersson HA, Singh RA, Barry MA. Activation of refractory $\mathrm{T}$ cell responses against hepatitis $\mathrm{C}$ virus core protein by ablation of interfering hydrophobic domains. Molecular therapy 2006; 13(2): 338-346.

12. Krishnadas DK, Li W, Kumar R, Tyrrell LJ, Agrawal B. In vitro activation and differentiation of naive CD4+ and CD8+ T cells into HCV core- and NS3-specific armed effector cells: a new role for $\mathrm{CD} 4+\mathrm{T}$ cells. Cell immunology 2009; 259(2): 141-149.

13. Guan J, Deng Y, Chen H, Yang Y, Wen B, Tan W. 
Immunogenicity and heterologous protection in mice with a recombinant adenoviral-based vaccine carrying a hepatitis $\mathrm{C}$ virus truncated NS3 and core fusion protein. Beijing Da Xие Xие Bao Zhe Xue She Hui Ke Xие Ban 2015; 31(1): 7-13.

14. Pouriayevali MH, Bamdad T, Aghasadeghi MR, Sadat SM, Sabahi F. Construction and immunogenicity analysis of hepatitis C virus (HCV) truncated NonStructural protein 3 (NS3) plasmid vaccine. Jundishapur journal of microbiology 2016; 9(3): e33909.

15. Hosseini SY, Sabahi F, Moazzeni SM, Modarressi MH, Saberi Firoozi M, Ravanshad M. Construction and preparation of three recombinant adenoviruses expressing truncated NS3 and core genes of hepatitis C virus for vaccine purposes. Hepatitis monthly 2012; 12(8): e6130.

16. Hosseini SY, Sabahi F, Moazzeni S, Modarressi M, Saberi-Firoozi M, Ravanshad M. Construction of an expression vector containing a novel fusion sequence from middle region of NS3 and truncated core genes of hepatitis C virus. Iranian journal of virology. 2011; 4(2): 17-27.

17. Hekmat S, Siadat SD, Aghasadeghi MR, Sadat SM, Bahramali G, Aslani MM, Mahdavi M, Shahbazi S. From in-silico immunogenicity verification to in vitro expression of recombinant Core-NS3 fusion protein of HCV. Bratislava medical journal 2017; 118(4): 189195.

18. Petrovsky N, Aguilar JC. Vaccine adjuvants: Current state and future trends. Immunology and cell biology 2004; 82(5): 488-496.

19. Nascimento IP, Leite LCC. Recombinant vaccines and the development of new vaccine strategies. Brazilian journal of medical and biological research 2012; 45(12): 1102-1111.

20. Tefit JN, Serra V. Outlining novel cellular adjuvant products for therapeutic vaccines against cancer. Expert review of vaccines 2011; 10(8):1207-1220.

21. Di Pasquale A, Preiss S, Tavares Da Silva F, Garçon N. Vaccine adjuvants: from 1920 to 2015 and beyond. Vaccines (Basel) 2015; 3(2): 320-343.

22. Khong H, Overwijk WW. Adjuvants for peptide-based cancer vaccines. Journal for immunotherapy of Cancer 2016; 4: 56.

23. Kuehn MJ, Kesty NC. Bacterial outer membrane vesicles and the host-pathogen interaction. Genes and development 2005; 19(22): 2645-2655.

24. Kulp A, Kuehn MJ. Biological functions and biogenesis of secreted bacterial outer membrane vesicles. Annual review of microbiology 2010; 64: 163-184.

25. Jan AT. Outer membrane vesicles (OMVs) of Gramnegative bacteria: A perspective update. Frontiers in microbiology 2017; 8: 1053.

26. Sharifat Salmani A, Siadat SD, Norouzian D, Izadi Mobarakeh J, Kheirandish M, Zanganeh M, Aghasadeghi MR, Nejati M, Hedayati MH, Moshiri A, Sadat SM. Outer membrane vesicle of Neisseria meningitidis serogroup $\mathrm{B}$ as an adjuvant to induce specific antibody response against the lipopolysaccharide of Brucella abortus S99. Annals of microbiology 2009; 59: 145-149.

27. Granoff DM. Review of meningococcal group B vaccines. Clinical infectious diseases 2010; 50(S2): S54-S56.

28. Delbaz SA, Siadat SD, Aghasadeghi MR, Piryaie M, Najar Peerayeh S, Mousavi SF, Moshiri A, Sadat SM, Zangeneh M, Nejati M, Kashanizadeh N, Bouzari S. Biological and immunological evaluation of Neisseria meningitidis serogroup A outer Membrane vesicle as vaccine candidates. Jundishapur journal of microbiology 2013; 6(4): 1-6.

29. Mirlashari MR, Høiby EA, Holst J, Lyberg T. Outer membrane vesicles from Neisseria meningitidis: effects on cytokine production in human whole blood. Cytokine 2001; 13(2): 91-97.

30. Lee TY, Kim CU, Bae EH, Seo SH, Jeong DG, Yoon SW, Chang KT, Kim YS, Kim, SH, Kim DJ. Outer membrane vesicles harboring modified lipid A moiety augment the efficacy of an influenza vaccine exhibiting reduced endotoxicity in a mouse model. Vaccine 2017; 35(4): 586-595.

31. Aghasadeghi MR, Sharifat Salmani A, Sadat SM, Javadi F, Memarnejadian A, Vahabpour R, Zabihollahi R, Moshiri A, Siadat SD. Application of outer membrane vesicles of Neisseria meningitidis serogroup B as a new adjuvant to induce strongly Th1-oriented responses against HIV-1. Current HIV research 2011; 9(8): 630635.

32. Moshiri A, Dashtbani-Roozbehani A, Najar Peerayeh S, Siadat SD. Outer membrane vesicle: A macromolecule with multifunctional activity. Human vaccines and immunotherapeutics 2012; 8(7): 953-955.

33. Kim OY, Park HY, Hong Dinh NT, Choi SJ, Lee J, Kim JH, Lee SW, Gho YS. Bacterial outer membrane vesicles suppress tumor by interferon- $\gamma$-mediated antitumor response. Nature Communications 2017; 8(1): 626.

34. Siegrist CA. Vaccine Immunology. Vaccines ( Six $^{\text {th }}$ edition). USA: Elsevier; 2013.

35. Yeap SP, Ahmad AL, Ooi BS, Lim JK. Electrosteric stabilization and its role in cooperative magnetophoresis of colloidal magnetic nanoparticles. Langmuir 2012; 28(42): 14878-14891.

36. Hekmat S, Aslani MM, Shafiee Ardestani M, Aghasadeghi MR, Siadat SD, Sadat SM, Mahdavi M, Shahbazi S, Asgarhalvaee F, Ghahari SMM, Tohidi F. Preparation and characterization of PLGA Nanoparticles containing recombinant Core-NS3 fusion protein of hepatitis $\mathrm{C}$ virus as a nano-vaccine candidate. Vaccine research 2017; 4(1 and 2): 13-18.

37. Lord SJ, Rajotte RV, Korbutt GS, Bleackley RC. Granzyme B: a natural born killer. Immunological reviews 2003; 193(1): 31-38.

38. Pardo J, Basque A, Brehm R, Wallich R, Naval J, Müllbacher A, Anel A, Simon MM. Apoptotic pathways are selectively activated by granzyme $\mathrm{A}$ and/or granzyme B in CTL mediated target cell lysis. Journal of cell biology 2004; 167(3): 457-468.

39. Schoenborn JR, Wilson CB. Regulation of interferongamma during innate and adaptive immune responses. 
Advances in immunology 2007; 96: 41-101.

40. Hwang ES, Hong JH, Glimcher LH. IL-2 production in developing Th1 cells is regulated by heterodimerization of RelA and T-bet and requires T-bet serine residue 508 . Journal of experimental medicine 2005; 202 (9): 12891300.

41. Mitsuyasu RT. The potential role of interleukin-2 in HIV. AIDS 2001; 15(Suppl 2): S22-S27.

42. Reier A1, Mitsuyasu RT. Use of interleukin-2 in immunotherapy of human immunodeficiency virus infection. BioDrugs 1998; 10(3): 215-225.
43. Khader SA, Gaffen SL, Kolls JK. Th17 cells at the crossroads of innate and adaptive immunity against infectious diseases at the mucosa. Mucosal immunology 2009; 2(5): 403-411.

44. Lin Y, Slight SR, Khader SA. Th17 cytokines and vaccine-induced immunity. Seminars in immunopathology 2010; 32(1): 79-90.

45. Khader SA, Gopal R. IL-17 in protective immunity to intracellular pathogens. Virulence 2010; 1(5): 423-427. 